\title{
Nitrogen Discharged from the Earth's Interior Regions
}

\author{
Mikio Fukuhara ${ }^{1,2,3}$ \\ ${ }^{1}$ Research Institute for Electromagnetic Materials, Sendai, Japan \\ ${ }^{2}$ Fracture and Reliability Research Institute, Tohoku University, Sendai, Japan \\ ${ }^{3}$ Green Device Laboratory, Waseda University, Tokyo, Japan \\ Email: fukuhara@cd.wakwak.com
}

Received September 12, 2013; revised October 11, 2013; accepted November 8, 2013

Copyright (C) 2014 Mikio Fukuhara. This is an open access article distributed under the Creative Commons Attribution License, which permits unrestricted use, distribution, and reproduction in any medium, provided the original work is properly cited. In accordance of the Creative Commons Attribution License all Copyrights (c) 2014 are reserved for SCIRP and the owner of the intellectual property Mikio Fukuhara. All Copyright (C) 2014 are guarded by law and by SCIRP as a guardian.

\section{ABSTRACT}

The abundant nitrogen in the Earth's atmosphere can be interpreted as the result of endothermic nuclear transmutation of carbon and oxygen atom pairs in $(\mathrm{Ca}, \mathrm{D}) \mathrm{CO}_{3}$ or $\mathrm{CaCO}_{3}$ aragonite lattice of Earth's crust from the Archean era to the present time, by physical catalytic help of excited electrons $e^{*}$ generated by stick sliding due to plate tectonics and geoneutrinos $v$ by the radioactive decay of elements such as uranium and thorium in Earth's mantle: ${ }^{12} \mathrm{C}+{ }^{16} \mathrm{O}+{ }^{2} \mathrm{D} \rightarrow 2{ }^{14} \mathrm{~N}+2{ }^{4} \mathrm{He}$ or ${ }^{12} \mathrm{C}+{ }^{16} \mathrm{O}+2 \mathrm{e}^{*}+2 v \rightarrow 2{ }^{14} \mathrm{~N}+{ }^{4} \mathrm{He}$ through a nuclear attraction effect that is due to deuteron catalysis of nitrogen formation. The relationship between the critical temperature $T$ and the critical pressure $P$ for the nuclear transmutation is expressed as $7253 \times \mathrm{e}^{-0.014 P}$, and the formation of nitrogen in the mantle is possible at temperatures $\geq 2510 \mathrm{~K}$ and pressure $\geq 58 \mathrm{GPa}$.

\section{KEYWORDS}

\section{Nitrogen; Earth; Nuclear Transmutation; Calcium Carbonate; Geoneutrinos; Excited Electrons; Tectonics}

\section{Introduction}

Nitrogen is an important component of all life-forms, but a significant question regarding the origin of the nitrogen that is abundant on Earth has not been resolved completely. The higher $\mathrm{N} / \mathrm{Kr}$ ratio [1] in the atmosphere puts severe constraints on the possibility of catastrophic degassing theory due to planetesimal impact [2]. From a similar evolution for atmospheric nitrogen and argon on Earth and Venus, the alternative possibility of a biological origin of nitrogen $[3,4]$ in the deoxidizing atmosphere of the early stages of the Earth appears to be poor. As far as the origin of the nitrogen of the Earth was not contributed to collision of planetesimals with abundance of nitrogen, we must inquire the answer into the Earth's crust and mantle. Indeed, nitrogen, like carbon dioxide, enters the atmosphere from the depth of the Earth in the degassing of the mantle [5-7].

\subsection{The Previous Works}

In previous papers [8,9], from wondering fact that the main binding energy per nucleon of stable nitrogen nuc- leus $(7.5 \mathrm{MeV})$ is lower than those $(7.7$ and $8.0 \mathrm{MeV})$ of carbon and oxygen ones, respectively [10], the origin of nitrogen is interpreted to be the result of the endothermic nuclear transmutation:

$$
{ }^{12} \mathrm{C}+{ }^{16} \mathrm{O} \rightarrow 2{ }^{14} \mathrm{~N} \quad Q=-10.47 \mathrm{MeV} .
$$

This reaction is due to two-body confinement of carbon and oxygen nuclei in $\mathrm{MgCO}_{3}$ carbonate lattice of the mantle, which is mediated by nuclear attraction caused by the catalysis of neutral pions, $\pi^{\circ}$, and taking into consideration the energy-momentum equilibrium [9]:

$$
{ }^{12} \mathrm{C}+{ }^{16} \mathrm{O}-2 \pi^{\mathrm{0}}=2{ }^{14} \mathrm{~N}
$$

which is based on an assumption that a parabolic increase in nitrogen content correlated to an abrupt decrease in carbon dioxide during the Archean era (3.8 to 2.5 billion years ago) [11-17]. Pions are responsible for all lowenergy nuclear interactions [18]; the pions within the nucleus allow the nucleonic species to bind together and transmute with each other [19]. Kenny [20] has termed Equation (2) as the "electropionic reaction". The neutral pion mass balance in Equation (2) is provided by emis- 
sion of two excited electrons [21], which are derived from the carbonate lattice:

$$
\begin{gathered}
\mathrm{e}^{-} \rightarrow \mathrm{e}^{*}, \gamma, \\
\gamma+\gamma=\pi^{\mathrm{o}} .
\end{gathered}
$$

where $\gamma$ is photon.

On the other hand, the electron reacts with deuteron to form neutral pion and an electron neutrino [20,22]:

$$
\mathrm{e}^{-}+2 \mathrm{D} \rightarrow \pi^{0}+v+\gamma,
$$

Fukuhara [23] has reported the following formula for the formation of helium:

$$
{ }^{2} \mathrm{D}+{ }^{2} \mathrm{D}+4 \mathrm{e}^{*}={ }^{4} \mathrm{He} .
$$

From Equations (3)-(6), we actually got the following weak dynamic interaction:

$$
{ }^{12} \mathrm{C}+{ }^{16} \mathrm{O}+2 \mathrm{e}^{*}+2 v \rightarrow 2{ }^{14} \mathrm{~N}+{ }^{4} \mathrm{He} .
$$

This reaction is facilitated by the electropionic attraction that is related to excited electron capture and neutral pion catalysis [22]. Since Equation (7) is a non-equilibrium (irreversible) equation, it does not obey the rules of parity and momentum balance. In the irreversible endothermic reaction proposed by Glansdorff and Prigogine [24], remarkable enhancement is expected on the basis of the thermal factor of $\exp (-\Delta \mathrm{G} / \mathrm{kT})$, where $\Delta \mathrm{G}$ is the change of Gibbs energy for the whole system. The excited electron $e^{*}$ in Equations (3) and (6) was generated by rapid fracture or sliding of carbonate crystals due to volcanic earthquake during the Archean era [25], and numerous neutrinos were derived from the universe, mainly from the young sun. Based on the previous pioneering studies, furthermore, we proposed an alternative possibility for the transmutation of nitrogen by the compression of $\mathrm{CO}_{3}$ anions in seawater at a critical depth of $10,250 \mathrm{~m}[26]$.

\subsection{Recent Discoveries}

The seismic electromagnetic activities, radio wave emission, lightening, etc., are explained by the electrical response of rocks with and without quarts [27,28]. Especially, exoelectron emission signals are associated with stick-slip of solids along heat flow under high pressure $[29,30]$.

From quantitative analysis of climate change that the total mass and pressure of Earth's atmosphere have fluctuated significantly over geological time scales (i.e. over hundreds of thousands to tens of millions of years), recently, Nikolov and Zeller [31] have asserted that the nitrogen generation through nuclear transmutation did not stop in the Archean era but continued up till now. That is because atmospheric mass gets constantly dispersed into space, and without a continuous resupply of nitrogen gasses from the crust, our atmosphere could not keep the pressure needed to support life on Earth.

On the other hand, Scientists at KamLAND [32] and Borexino [33] have detected signals of geoneutrinos produced in deep in Earth's mantle by the radioactive decay of elements such as uranium and thorium at 2005 and 2007, respectively. In sharp contrast to solar neutrinos, a consistent emission of the geoneutrinos suggests a significant enhancement of the reaction rate for formation of nitrogen. From these recent experimental data, we must revise previous explanation for period of duration in nitrogen formation, using calcium carbonates $\mathrm{CaCO}_{3}$ of main component of the crust.

\section{Deuteron Catalysis of Nitrogen Formation, Based on Double $\beta$ Decay}

Our next interest lies in studying the other possible formation of nitrogen by dynamic interactions between carbon and oxygen atoms in the geophysical environment of a carbonate $(\mathrm{Ca}, \mathrm{D}) \mathrm{CO}_{3}$ or $\mathrm{CaCO}_{3}$ lattice in mantle under high-temperature and high-pressure conditions, based on double $\beta$ decay process, where $\mathrm{D}$ is deuteron.

We have briefly described neutral pion catalysis for nitrogen formation, which is based on ordinary double $\beta$ decay [26]:

$$
(Z, A) \rightarrow(Z+2, A)+2 e^{-}+2 v,
$$

where $\mathrm{Z}$ and $\mathrm{A}$ are atomic and mass numbers, respectively. It has been observed for 11 isotopes, ${ }^{48} \mathrm{Ca}$, ${ }^{76} \mathrm{Ge}$, ${ }^{82} \mathrm{Se},{ }^{96} \mathrm{Zr},{ }^{100} \mathrm{Mo},{ }^{116} \mathrm{Cd},{ }^{128} \mathrm{Te},{ }^{136} \mathrm{Xe},{ }^{150} \mathrm{Nd}$ and ${ }^{238} \mathrm{U}$. [34] Indeed, the double $\beta$ decay of ${ }^{82} \mathrm{Se}$ and ${ }^{128} \mathrm{Te}$ isotopes was detected in the geochemical experiments [35].

On the other hand, these pairs can be also generated by the double $\beta$ decay of deuteron [36],

$$
{ }^{2} \mathrm{D} \rightarrow{ }^{4} \mathrm{He}+2 \mathrm{e}^{-}+2 v .
$$

From Equations (7) and (8), we get a non-equilibrium formula:

$$
{ }^{12} \mathrm{C}+{ }^{16} \mathrm{O}+{ }^{2} \mathrm{D} \rightarrow 2{ }^{14} \mathrm{~N}+2{ }^{4} \mathrm{He} .
$$

Since occurrence of two $\mathrm{e}^{-}-v$ pairs can produced by the double $\beta$ decay, the physical role of neutral pions is equivalent to the addition of the $\mathrm{e}^{-}$and $v$ pair, as physical catalysts of an endothermic nuclear transmutation. The volatile helium gases generated in reaction. Equation (10) would be released from the Earth's atmosphere.

It is noteworthy that deuterium in cometary water is enriched by factor of at least 10 relative to the $\mathrm{D} / \mathrm{H}$ ratio (0.0017) of the seawater on the present Earth [37]. If seawater originated from the water-ice found in comets or meteorites [38], it seems reasonable to assume that the primitive seawater, which was abundant in heavy water, played a definitive role in the formation of nitrogen. The primitive seawater also formed $\mathrm{D}_{2} \mathrm{CO}_{3}$ for the absorption 
of $\mathrm{CO}_{2}$. When the $\mathrm{D}_{2} \mathrm{CO}_{3}$ is inserted into the calcite lattices of the crust of the Earth, we can assume a configuration and a cross-section of the D-inserted compound (Ca, D) $\mathrm{CO}_{3}$ (Figure 1) [39]. High temperature and high pressure accelerate the process described in Equation (9) by endothermic reaction.

Assuming that the existence of the deuteron induces the formation of nitrogen, as well as the neutral pion catalysis described in Equation (7) [8], a similar result would be obtained for ( $\mathrm{Ca}, \mathrm{D}) \mathrm{CO}_{3}$ on the basis of dynamic at traction, by combining the effects of screening of free electrons and thermal activation. However, indeed, Equation (7) would be dominated at present time, because of tiny deuterium content in the seawater on the present Earth.

\section{Nitrogen Formation in Aragonite Phase at High Pressure and High Temperature}

Since we can estimate that the calcite form, which is thermodynamically stable under pressure below $100 \mathrm{GPa}$ and temperature between 3000 and $1000 \mathrm{~K}$, is orthorhombic aragonite from $P-T$ phase diagram reported by Suito et al. [40], we used an extrapolated formula $\rho=$ $0.113 P+2.71$ for high pressure density $\rho$ of aragonite, due to the lack of crystal lattice data for aragonite subjected to pressure $P>7.7 \mathrm{GPa}$. The densities of (Ca, D) $\mathrm{CO}_{3}$ or $\mathrm{CaCO}_{3}$ at 50, 60, 70, 80, 90 and $100 \mathrm{GPa}$ can be estimated as 8.38, 9.51, 10.64, 11.77, 12.91 and 14.04 $\mathrm{Mg} / \mathrm{m}^{3}$, respectively. From Equation (A1) in Appendix,

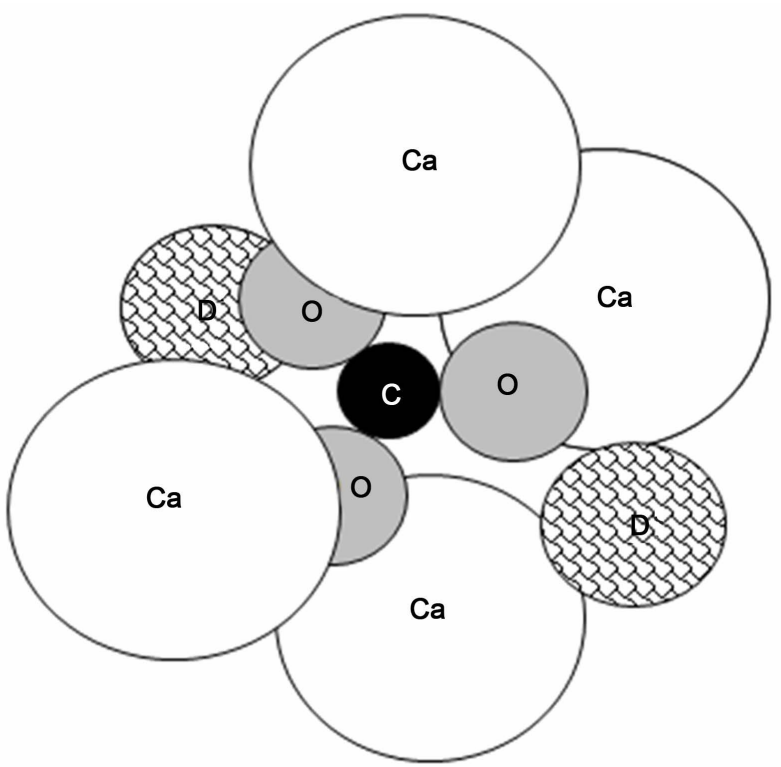

Figure 1. Configuration of (Ca, D)CO $\mathrm{CO}_{3}$ group atoms in (111) calcite crystal planes. The $\mathrm{CO}_{3}$ group lies exactly midway between the planes on which is sandwiched by $(\mathrm{Ca}, \mathrm{D})$ planes, and in consequence the (111) planes have the structure (Ca, D)- $\mathrm{CO}_{3}-(\mathrm{Ca}, \mathrm{D})$. The atomic sizes are not necessarily to scale. we can assume the corresponding $\mathrm{C}-\mathrm{O}$ bond distances $2 r_{1}$ $=0.1009,0.0968,0.0932,0.0900,0.0873$ and $0.0850 \mathrm{~nm}$ [41], respectively. However, the smallest distance $(0.0850$ $\mathrm{nm})$ is still large in the terms of the critical radius $(0.079$ $\mathrm{nm})$ required for a dynamic nuclear reaction [19].

Since the pressures of 50,60, 70, 80, 90 and $100 \mathrm{GPa}$ correspond to distances of around 1110, 1340, 1570, 1800, 2030 and $2270 \mathrm{~km}$, respectively, below the surface of the present Earth, we can estimate the corresponding temperatures as 1105, 1439, 1774, 2109, 2443 and 2778 $\mathrm{K}$, respectively [42]. From the effect of temperature on the reaction rate $k$ (Equation (A2) in Appendix) under the repulsive interaction potential between the atoms, we get the following example of shrunken distance at $80 \mathrm{GPa}$ (Equation (A4) in Appendix):

$$
\begin{aligned}
2 r_{2} & \cong 2 \times 0.862 r_{1}=2 \times 0.862 \times 0.6128 \times r_{o} \\
& =0.1554 \mathrm{~nm} .
\end{aligned}
$$

This radius $(0.078 \mathrm{~nm})$ is somewhat smaller than the critical radius $(0.079 \mathrm{~nm})$ required for a dynamic nuclear reaction. Thus, the relationship between the critical temperature $T$ and the critical pressure $P$ for the reaction is expressed as

$$
T=7253 \exp ^{-0.014 P}
$$

Since the region with this temperature-pressure profile corresponds to the zone of diamond formation in mantle [43], the relationship in Equation (12) is shown in Figure 2, along with the diamond formation lines, the actual temperature-pressure profile of the Earth [44], and estimated $P-T$ phase boundary line between aragonite and disordered calcite [40]. The critical temperature and pressure, which correspond to the critical radius for the dynamic reaction is $2510 \mathrm{~K}$ and $58 \mathrm{GPa}$, leading to man-

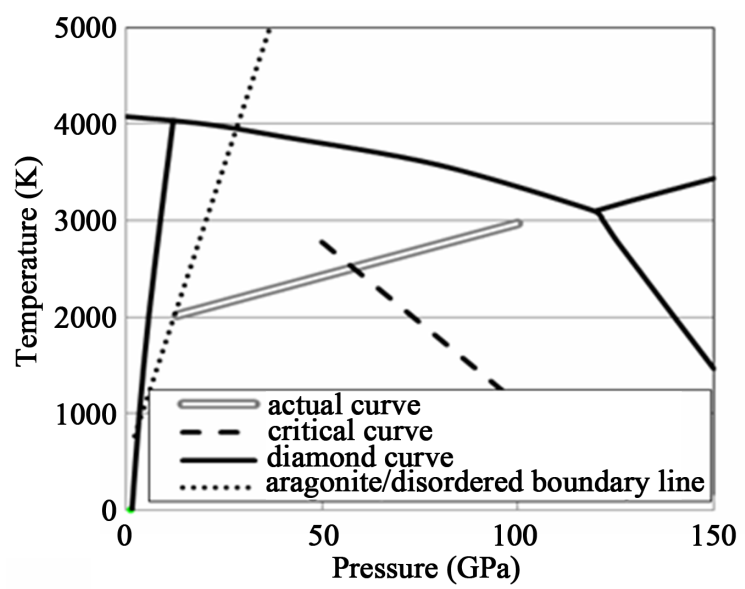

Figure 2. Critical temperature-pressure curve for nitrogen transmutation, and the actual temperature-pressure curve, diamond formation lines and estimated $P$ - $T$ phase boundary line between aragonite and disordered calcite in the mantle. 
tle depth of $1290 \mathrm{~km}$ [4]. Therefore, it is possible that the dynamic reaction occurs in an upper portion of the lower mantle. The conditions required for the formation of nitrogen are more stringent than those for diamonds. Even if in case $\left(\mathrm{CaCO}_{3}\right)$ of deuteron free, highly active tectonic plate movement accompanied by convection currents in the Earth's mantle (asthenosphere) would enhance the nitrogen reaction via dynamic collision-induced fractonuclear transmutation [45] in Equation (7). Furthermore, the subduction of lithosphere due to plate tectonics would deliver high quantities of fresh calcium carbonates to the upper mantle that serve as a raw material for large amounts of nitrogen production. Schematic figure for nitrogen for mation and discharge by convection currents of asthenosphere is presented at Figure 3. In collision zone of the convection currents, nitrogen would be formed in lattices of aragonite carried by subduction of lithosphere by physical catalytic help of excited electrons $\mathrm{e}^{*}$ generated by stick slipping of aragonite rocks and geoneutrinos produced in deep in Earth's mantle by radioactive decay of elements. The nitrogen and helium gases discharge by volcanic and hydrothermal activities into the atmosphere. Indeed, Craig et al. [46] have observed high ( 16 times) helium isotope concentration ratio $\left({ }^{3} \mathrm{He} /{ }^{4} \mathrm{He}\right)$ at the volcano area. The volatile helium gases would be released from the Earth's atmosphere to the universe. Even if the convection current in the upper mantle is viscous fluid, the nuclear reaction could be promoted. In fact, fusion reaction ${ }^{6} \mathrm{Li}(\mathrm{d}, \alpha){ }^{4} \mathrm{He}$ and ${ }^{2} \mathrm{H}(\mathrm{d}, \mathrm{p})$

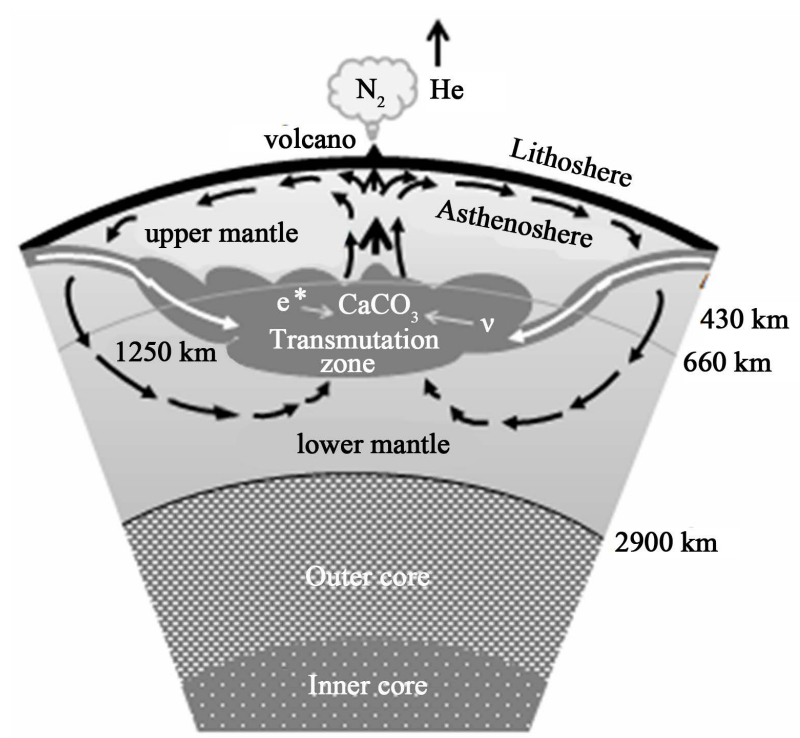

Figure 3. Convection currents in the Earth's mantle and their role in nitrogen formation and discharge. Nitrogen formation can be interpreted as the result of endothermic nuclear transmutation of carbon and oxygen atom pairs in aragonite lattice carried by subduction of lithosphere, by physical catalytic help of excited electrons $e^{*}$ generated by stick slipping of aragonite rocks and geoneutrinos produced in deep in Earth's mantle by radioactive decay of elements.
${ }^{3} \mathrm{H}$ with $\sim 6.83 \times 10^{6} \mathrm{~K}$ were measured in liquid Li acoustic (ultrasonic) cavitation [47].

Here, we describe the natural conditions for diamond formation. It is well known that natural diamonds crystallize directly from kimberlite rock melts that are rich in calcite and found at depths of $1500 \mathrm{~km}$ or more inside the Earth. The melts are essentially saturated in carbon dioxide gas at high pressures over $30 \mathrm{GPa}$ and temperatures $\geq 763 \mathrm{~K}$ in deep in the Earth's mantle, since the ${ }^{12} \mathrm{C} /{ }^{13} \mathrm{C}$ ratio of a diamond shows that it arises from carbon dioxide [46]. Furthermore we note that platesets of polycyanogen $\left(\mathrm{C}_{3} \mathrm{~N}\right)$ are dispersed in kimberlite rocks [48]. The type Ia diamond contains maximally $2 \%$-mil nitrogen [49]. Thus, the nitrogen impurities in diamonds may be the result of nuclear transmutation of $\mathrm{CO}_{2}$ in the melt. Furthermore, it is known that nitrogen is distributed extensively throughout the silicate phase of the Earth's crust and mantle [50].

The scheme for nitrogen transmutation of $(\mathrm{Ca}, \mathrm{D}) \mathrm{CO}_{3}$ or $\mathrm{CaCO}_{3}$ resembles that observed for the $\mathrm{Pd} /$ complexes, which are composed of $\mathrm{Pd}$ and $\mathrm{CaO}$ thin films, and the Pd substrate, after the Pd complexes are subjected to $\mathrm{D}_{2}$ gas permeation [51]. Although they have not described directly the transmutation effect brought about by the Ca element, they could not obtain a similar result using $\mathrm{MgO}$ in place of $\mathrm{CaO}$ [52]. Therefore, we believe that $\mathrm{Ca}$ is the common driving element for nuclear transmutation. In particular, the possibility exists that the electrons are derived from calcium elements with many electrons, such as $3 s^{2}, 3 p^{6}$ and $4 s^{2}$ [53]. The emission of charged particles and acceleration of the electrical charge may enhance nuclear transmutation, such as a fractofusion. If nitrogen was derived from carbon and oxygen, geologically active planets with abundant both atoms would have generated nitrogen. This is a very interesting possibility, since carbon and nitrogen are the two major elements in all life systems [54].

\section{Conclusion}

We have calculated the relationship between the critical temperature $T$ and the critical pressure $P$ for the endothermic nuclear transmutation of carbon and oxygen atom pairs in (Ca, D) $\mathrm{CO}_{3}$ or $\mathrm{CaCO}_{3}$ aragonite lattice of Earth's mantle (asthenosphere) from the Archean era to the present time, by physical catalytic help of excited electrons generated by stick slipping due to tectonics and geoneutrinos by the radioactive decay of elements such as uranium and thorium in Earth's mantle. The critical temperature and pressure for the nitrogen formation belong to the diamond formation region. In subsequent paper, we will address experimental problem whether formation of nitrogen occurs from a calcite specimen with and without $\mathrm{D}$ in diamond-anvil high-pressure cell under temperature over $2500 \mathrm{~K}$ and pressure over $60 \mathrm{GPa}$ or 
not; attention will be given to the generation of physical catalysis of excited electrons and neutrinos.

\section{REFERENCES}

[1] R. O. Pepin, "Atmospheric Compositions: Key Similarities and Differences,” In: S. K. Atreya, et al., Ed., Origin and Evolution of Planetary and Satellite Atmospheres, University of Arizona Press, Tucson, 1989, pp. 291-305.

[2] J. A. Tyburezy, B. Frisch and T. J. Ahrens, Earth and Planetary Science Letters, Vol. 80, 1986, pp. 201-207. http://dx.doi.org/10.1016/0012-821X(86)90104-4

[3] C. C. Delwiche, Scientific American, Vol. 223, 1970, pp. 137-146. http://dx.doi.org/10.1038/scientificamerican0970-136

[4] P. Warneck, "Chemistry of the Natural Atmosphere," 2nd Edition, Academic Press, New York, 1998, p. 605.

[5] D. E. White and G. A. Waring, "Volcanic Emanations," U. S. Geological Survey Prof. Paper, 1963, p. 440.

[6] M. I. Budyko, A. B. Ronov and A. L. Yanshin, "History of the Earth's Atmosphere," Springer-Verlag, New York, 1985, p. 2, 16.

[7] T. Ogawa, "Physical Chemistry of Atmosphere," Tokyo Do, Tokyo, 1991, p. 4. (in Japanese)

[8] M. Fukuhara, "Possible Nuclear Transmutation of Nitrogen in Atmosphere," Proceedings of the 4th Meeting of Japan CF Research Society, Iwate University, 11-12 December 2002, pp. 63-67.

[9] M. Fukuhara, Nuovo Cimento, Vol. 27C, 2004, pp. 99113.

[10] A. Bohr and B. R. Mottelson, "Nuclear Structure," Single-Particle Motion, Vol. 1, W. A. Benjamin, Amsterdam, 1969, p. 168.

[11] A. Benlow and A. Meadows, Journal of Astrophysics and Space Science, Vol. 46, 1977, pp. 293-300. http://dx.doi.org/10.1007/BF00644376

[12] T. Owen, R. D. Cess and V. Ramanathan, Nature, Vol. 277, 1979, pp. 640-642. http://dx.doi.org/10.1038/277640a0

[13] C. J, Allégre, B. Dupré and O. Brévart, Transactions of the Royal Society of London, Series A, Vol. 306, 1982, pp. 49-59.

[14] M. I. Budyko, A. B. Ronov and A. L. Yanshin, "History of the Earth's Atmosphere,” Springer-Verlag, New York, 1985, p. 16, 128.

[15] J. F. Kasting and T. P. Ackerman, Science, Vol. 234, 1986, pp. 1383-1385. http://dx.doi.org/10.1126/science.11539665

[16] J. F. Kasting, Precambrian Research, Vol. 34, 1987, pp. 205-229. http://dx.doi.org/10.1016/0301-9268(87)90001-5

[17] H. Ohmoto, Kagaku (in Japanese), Vol. 14, 1994, pp. 360-370.

[18] D. F. Measday and G. A.Miller, Annual Review of Nuclear and Particle Science, Vol. 29, 1979, pp. 121-160.

[19] S. E. Jones, E. P. Palmer, J. B. Czirr, D. L. Decker, J. M.
Thorne, S. F. Taylor and J. Rafelsli, Nature, Vol. 338, 1989, pp. 737-740. http://dx.doi.org/10.1038/338737a0

[20] J. P. Kenny, Fusion Technology, Vol. 19, 1991, pp. 547551.

[21] R. P. Feymann, “The Theory of Fundamental Processes," Benjamin/Cummings Publishing Company, San Francisco, 1961, p. 37.

[22] M. Fukuhara, Fusion Science and Technology, Vol. 43, 2003, pp. 128-133.

[23] M. Fukuhara, "Possible Coexistence of Electron and Electron Neutrino in Nucleus and Its Effect on D-D Cold Fusion into Helium," Proceedings of the 6th Meeting of Japan CF Research Society, Tokyo Inst. Technology, Tokyo, 27-28 April 2005, pp. 53-57.

[24] P. Glansdorff and I. Prigogine, “Thermodynamic Theory of Structure, Stability and Fluctuations,” Wiley-Interscience, London, 1971, p. 1.

[25] C. J. Allégre and S. H. Schneider, Scientific American, Vol. 271, 1994, pp. 44-51. http://dx.doi.org/10.1038/scientificamerican1094-66

[26] M. Fukuhara, "Possible Nuclear Transmutation of Nitrogen in Atmosphere of Earth (II)," Proceedings of the 7th Meeting of Japan CF Research Society, Kagoshima University, Kagoshima, 27-28 April 2006, pp. 71-73.

[27] Y. Enomoto and H. Hashimoto, Nature, Vol. 346, 1990, pp. 641-643.

[28] F. T. Freund, A. Takeuchi, B. W. S. Lau, A. Al-Manaseer, C. C. Fu, N. A. Bryant and D. Ouzounov, Earth Discuss, Vol. 1, 2006, pp. 97-121. www.electronic-earth-discuss.net/1/97/2006/

[29] J. N. Brune, S. Brown and P. A. Johnson, Technophysics, Vol. 218, 1993, pp. 59-67. http://dx.doi.org/10.1016/0040-1951(93)90259-M

[30] A. Tsutsumi and N. Shirai, Tectonophysics, Vol. 450, 2008, pp. 79-84. http://dx.doi.org/10.1016/j.tecto.2008.01.001

[31] N. Nikolov and K. Zeller, "US Forest Services,” 2013, Private Communication.

[32] T. Araki, et al., Nature, Vol. 436, 2005, pp. 499-503.

[33] G. Bellini, et al., Physics Letters B, Vol. 687, 2010, pp. 299-304.

[34] J. Beringer, et al., Physical Review D, Vol. 86, 2012, Article ID: 010001.

[35] A. S. Barabash, Physics of Atomic Nuclei, Vol. 74, 2011, pp. 603-613.

[36] T. D. Lee and C. S. Wu, Annual Review of Nuclear Science, Vol. 15, 1965, pp. 381-476. http://dx.doi.org/10.1146/annurev.ns.15.120165.002121

[37] D. Bocklee-Morvan, D. Gautier, D. C. Lis, K. Young, J. Keene, T. Phillips, T. Owen, J. Crovisier, P. F. Goldsmith, E. A. Bergin, D. Despois and A. Wootten, Icarus, Vol. 133, 1998, pp. 147-162. http://dx.doi.org/10.1006/icar.1998.5916

[38] L. A. Frank, J. B. Sigwarth and J. D. Craven, Geophysical Research Letters, Vol. 13, 1986, pp. 303-310. http://dx.doi.org/10.1029/GL013i004p00303 
[39] W. L. Bragg, Proceedings of the Royal Society of London. Series A, Vol. 105, 1924, pp. 16-39.

[40] K. Suito, J. Namba, T. Horikawa, Y. Taniguchi, N. Sakurai, M. Kobayashi, A. Onodera, O. Shimomura and T. Kikegawa, American Mineralogist, Vol. 86, 2001, pp. 997-1002.

[41] O. Kennard, "International Tables for X-ray Crystallography,” International Union of Crystallography, Kynoch Press, Birmingham, 1968, p. 276.

[42] S. Glasstone and D. Lewis, "Elements of Physical Chemistry,” D. Van Nostrand Company, Princeton, 1960, p. 632.

[43] F. P. Bundy, "Solid State Physics under Pressure: Recent Advance with Devices," Scientific Publishing Company, Dordrecht, 1985, p. 1.

[44] E. Ohtani and T. Irifune, "Basic Measurement and Application of Solid Planet Material Science,” In: H. Takeda, H. Kitamura and M. Miyamoto, Eds., Science House, Tokyo, 1994, p. 187.

[45] P. R. Price, Nature, Vol. 343, 1990, pp. 542-544. http://dx.doi.org/10.1038/343542a0

[46] H. Craig, Geochimica et Cosmochimica Acta, Vol. 3, 1953, pp. 53-92. http://dx.doi.org/10.1016/0016-7037(53)90001-5

[47] Y. Toriabe, E. Yoshida, J. Kasagi and M. Fukuhara, Physical Review C, Vol. 85, 2012, Article ID: 054620.

[48] C. Frondel and G. C. Kennedy, "Encyclopedia of the Geological Sciences,” In: D. N. Lapedes, Ed., McGrawHill, New York, 1977, P. 155.
[49] S. Satoh, S. Yazu, K. Tsuji, A. Hara, N. Urakawa and A. Yoshida, Sumitomo Electric Technical Review, Vol. 129, 1986, pp. 99-106.

[50] J. A. Brandes, N. Z. Boctor, G. D. Cody, B. A. Cooper, R. M. Hazen and H. S. Yoder Jr., Nature, Vol. 395, 1998, pp. 365-367. http://dx.doi.org/10.1038/26450

[51] Y. Iwamura, M. Sakano and T. Itoh, Japanese Journal of Applied Physics, Vol. 41, 2002, pp. 4642-4650. http://dx.doi.org/10.1143/JJAP.41.4642

[52] Y. Iwamura, Mitsubishi Heavy Industries, Private Communication, 2004.

[53] M. Fukuhara, Japanese Journal of Applied Physics, Vol. 46, 2007, pp. 3035-3038. http://dx.doi.org/10.1143/JJAP.46.3035

[54] K. Nealson, University of South California, Los Angeles, Private Communication, 2006.

[55] Ya. B. Zedlovich and I. D. Novikov, "Relativistic Astrophysics,” Vol. 1, Chicago University Press, Chicago, 1971, p. 161.

[56] M. Fukuhara and G. W. Smith, II, Physica Status Solidi, Vol. 156, 1989, pp. 583-596. http://dx.doi.org/10.1002/pssb.2221560222

[57] J. Schwinger, Physical Review A, Vol. 24, 1981, pp. 23532361. http://dx.doi.org/10.1103/PhysRevA.24.2353

[58] C. Kittel, "Introduction to Solid State Physics," Sixth Edition, John Wiley \& Sons, New York, 1986, p. 62.

[59] Wikipedia, 2013. http://en.wikipedia.org/wiki/Nuclear_transmutation 


\section{Appendix}

\section{Appendix A: Confinement by Screening of Condensed Electrons and High Temperature}

In order to evaluate necessary condition of nuclear transmutation process for nitrogen formation from the $(\mathrm{Ca}, \mathrm{D})$ $\mathrm{CO}_{3}$ (aragonite) lattice, we consider confinement effect by screening of condensed electrons and high temperature. It should be noted that at pressures in excess $0.5 \mathrm{Mg}$ $\mathrm{cm}^{-3}$ the individual electron shell structures of the atoms vanish and are replaced by a statistical distribution of the electrons in the field of the atomic nuclei [55]. These electrons in the outer shell behave as if they are free particles [56]. Therefore, by analogy, we infer that the outer-shell electrons of carbon and oxygen atoms in (Ca, D) $\mathrm{CO}_{3}$ lattices behave as free electrons, and the resulting screening effect serves as relief of the Coulomb repulsive forces between the carbon and oxygen nuclei. Since this type of interelectron Coulomb interaction alters the electron shell behavior under the action of an electromagnetic field, we apply the Thomas-Fermi (TF) approximation to the screening effect of the $(\mathrm{Ca}, \mathrm{D}) \mathrm{CO}_{3}$ lattice below the surface of the Earth [42]. For a multi-electron atom, the TF theory [57] gives (in atomic units)

$$
V(r)=-Z e^{2} / r \Phi(r / b),
$$

where $V(r)$ is the potential energy, and $Z$ is the atomic number.

We then consider the effect of temperature on the reaction rate $k$. The rate can be expressed by the Arrhenius equation [58]:

$$
k=\left(k_{b} f_{N}^{2} / h f_{c} f_{o}\right) \mathrm{e}^{-E / R T}
$$

where the $f_{C}, f_{O}$, and $f_{N}$ are the partition functions of ${ }^{12} \mathrm{C}$, ${ }^{16} \mathrm{O}$, and ${ }^{14} \mathrm{~N}$, respectively, and $k_{b}, R$, and $E$ are the Boltzman constant, gas constant, and activation energy of the reaction, respectively. When $f_{C} \fallingdotseq f_{O} \fallingdotseq f_{N}$, a ratio of the rates at temperature $T_{0}$ and $T_{1}$ can be described as follows:

$$
\frac{k_{1}}{k_{0}}=\frac{T_{1}}{T_{0}} \mathrm{e}^{\frac{E}{R}\left(\frac{\left(T_{1}-T_{0}\right)}{T_{0} T_{1}}\right)}
$$

In comparison with $T_{0}=300 \mathrm{~K}$ and $T_{1}=1105,1439$, 1774, 2109, 2443 and $2778 \mathrm{~K}$, we get:

$$
k_{1} / k_{2} \fallingdotseq 3.68,4.80,5.91,7.03,8.14 \text { and 9.26, }
$$

respectively. According to the first principle, the following potential form expresses the repulsive interaction between the atoms [18]:

$$
U(R)=-B / r^{12},
$$

where $B$ is an empirical parameter.

\section{Appendix B: Cold Nuclear Transmutation}

Nuclear transmutation is the conversion of an atom of one chemical element or isotope into an atom of another [59]. This reaction occurs either through artificial or natural nuclear reactions. The former is nuclear reaction by bombardment with high speed particles. The first artificial transmutation was achieved by Rutherford by bombarding nitrogen with alpha particles:

$$
{ }^{14} \mathrm{~N}+{ }^{4} \mathrm{He} \rightarrow{ }^{17} \mathrm{O}+{ }^{1} \mathrm{H}
$$

The another example is the production of radioactive ${ }^{14} \mathrm{C}$ used in radiocarbon dating in the atmosphere by the neutrinos in cosmic rays.

$$
{ }^{14} \mathrm{~N}+{ }^{1} \mathrm{n} \rightarrow{ }^{14} \mathrm{C}+{ }^{1} \mathrm{H}
$$

The latter is natural process that an unstable nucleus of an atom breaks apart into smaller parts through radioactive decay.

$$
\begin{array}{r}
{ }^{235} \mathrm{U} \rightarrow{ }^{231} \mathrm{Th}+{ }^{4} \mathrm{He}(\alpha \text { decay }) \\
{ }^{131} \mathrm{I} \rightarrow{ }^{131} \mathrm{Xe}+{ }^{0} \mathrm{e}(\beta \text { decay })
\end{array}
$$

The endothermic nuclear transmutation of Equation (7) or Equation (10) would be promoted by physical catalysis of by physical catalytic help of excited electrons $\mathrm{e}^{*}$ generated by stick slipping due to plate tectonics and geoneutrinos $v$ by the radioactive decay of elements in Earth's mantle or deuteron catalysis, respectively, as cold nuclear transmutation at lower temperature and pressure of around $2510 \mathrm{~K}$ and $58 \mathrm{GPa}$ in the Earth's mantle (asthenosphere). 